\title{
Sotise a huit personnaiges [Le Nouveau Monde], édition critique par Olga Anna Duhl
}

\section{Michele Mastroianni}

\section{Q OpenEdition}

1 Journals

\section{Edizione digitale}

URL: http://journals.openedition.org/studifrancesi/32911

DOI: 10.4000/studifrancesi.32911

ISSN: 2421-5856

\section{Editore}

Rosenberg \& Sellier

\section{Edizione cartacea}

Data di pubblicazione: 1 décembre 2005

Paginazione: 621

ISSN: 0039-2944

\section{Notizia bibliografica digitale}

Michele Mastroianni, «Sotise a huit personnaiges [Le Nouveau Monde], édition critique par Olga Anna Duhl», Studi Francesi [Online], 147 (XLX | III) | 2005, online dal 30 novembre 2015, consultato il 18 avril 2021. URL: http://journals.openedition.org/studifrancesi/32911 ; DOI: https://doi.org/10.4000/ studifrancesi.32911

Questo documento è stato generato automaticamente il 18 avril 2021.

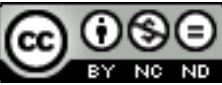

Studi Francesi è distribuita con Licenza Creative Commons Attribuzione - Non commerciale - Non opere derivate 4.0 Internazionale. 


\title{
Sotise a huit personnaiges [Le Nouveau Monde], édition critique par Olga Anna Duhl
}

\author{
Michele Mastroianni
}

\section{NOTIZIA}

Sotise a huit personnaiges [Le Nouveau Monde], édition critique par OLGA ANNA DUHL, Genève, Droz («Textes Littéraires Français», 573), 2005, pp. 344.

1 La Sotise a huit personnaiges, composta a Tolosa verso il 1507, è un testo di grande importanza per ricostruire il gioco complesso di potere e cultura, nel momento in cui Luigi XII sviluppa una violenta politica antipapale (nel conflitto che lo oppone a Giulio II), politica peraltro appoggiata da parecchi storiografi-rhétoriqueurs coinvolti nell'ambiente di corte, quali Jean Marot, Jean Lemaire, Jean d'Auton, Jean Bouchet, Pierre Gringore, André de La Vigne. Ad alcuni di questi autori (in particolare a Jean Bouchet e ad André de La Vigne) fu attribuita successivamente la Sotise. O. A. Duhl analizza accuratamente le varie attribuzioni - in particolare quella ad André de La Vigne, avanzata da Émile Picot, accettata per un secolo - per respingerle e giungere alla conclusione che si tratterebbe di una elaborazione a più mani, nello stile dei rhétoriqueurs. Opera di propaganda antipapale, nel contesto dello scontro Luigi XIIGiulio II, la Sotise è anche opera che, in qualche modo contraddittoriamente, lancia degli attacchi ad hominem contro il re stesso e il suo ministro, il cardinale d'Amboise, nella prospettiva della difesa delle libertà della Chiesa Gallicana. Questa ambivalenza rende il testo interessante testimonianza della complessità delle strategie politiche $\mathrm{e}$ apre interrogativi su fatti editoriali significativi, come la pubblicazione, a Parigi, con privilegio reale di un testo composto a Tolosa, ove avrebbe potuto essere pubblicato con privilegio parlamentare locale. La studiosa, offrendo una nuova edizione critica, dopo quella di Picot (d'inizio Novecento), basata sulla sola stampa conosciuta (BN, Rés. Yf 2934), discute ampiamente e con ricchezza di dati tutti i problemi storici e ideologici 
concernenti la Sotise, in una ampia introduzione (pp. 17-171) che è una vera e propria monografia. In questa introduzione si analizza anche l'opera in questione sotto l'aspetto strutturale, letterario e linguistico, con l'accompagnamento di un ottimo glossario. Lo studio grammaticale, sintattico e lessicale, nonché una notevole indagine sulla versificazione, rendono il lavoro di $\mathrm{O}$. A. Duhl un utilissimo strumento di lavoro per lo storico della lingua. 